University of Washington Tacoma

UW Tacoma Digital Commons

Social Work \& Criminal Justice Publications

Social Work \& Criminal Justice

2019

\title{
Young Adult Reflections on the Impact of Parental Incarceration and Reentry
}

Diane S. Young

University of Washington Tacoma, youngd4@uw.edu

Carrie Jefferson Smith

Follow this and additional works at: https://digitalcommons.tacoma.uw.edu/socialwork_pub

\section{Recommended Citation}

Young, Diane S. and Jefferson Smith, Carrie, "Young Adult Reflections on the Impact of Parental Incarceration and Reentry" (2019). Social Work \& Criminal Justice Publications. 512.

https://digitalcommons.tacoma.uw.edu/socialwork_pub/512

This Article is brought to you for free and open access by the Social Work \& Criminal Justice at UW Tacoma Digital Commons. It has been accepted for inclusion in Social Work \& Criminal Justice Publications by an authorized administrator of UW Tacoma Digital Commons. 


\title{
Young Adult Reflections on the Impact of Parental Incarceration and Reentry
}

\author{
Diane S. Young, Ph.D. (Corresponding Author) \\ University of Washington - Tacoma \\ Social Work and Criminal Justice Program \\ 1900 Commerce St. \\ Box 358425 \\ Tacoma, WA 98402 \\ 253.692.4703 \\ youngd4@uw.edu
Carrie Jefferson Smith, DSW
Syracuse University
School of Social Work
284 White Hall
Syracuse, NY 13244
315.443 .5552
cjsmit04@syr.edu

We would like to acknowledge the contributions of the young people who shared their experiences with us. Without them this work would not have been possible.

Financial support was provided by the University of Washington - Tacoma Social Work and Criminal Justice Program and the Syracuse University School of Social Work. 
Young Adult Reflections on the Impact of Parental Incarceration and Reentry

\begin{abstract}
Little is known about the continuing effects of childhood parental incarceration into young adulthood. Fourteen young adults who experienced parental incarceration during adolescence shared their experiences through individual interviews focused on the following qualitative research question: In what ways do young adults believe they have been impacted in young adulthood by the earlier experiences of parental incarceration and reentry? Findings indicate that most relationships with previously incarcerated parents remain tenuous. Participants describe ongoing struggles to develop trusting relationships, manage negative emotions, and stay out of trouble. Findings have implications for assisting young adults and families affected by criminal justice involvement.
\end{abstract}

Key Words: Parental Incarceration; Reentry; Young Adults; Children of Incarcerated Parents; Adolescents 
Parental incarceration and family reentry affect a large number of children in the United States, including a disproportionate number of the poor and certain racial and ethnic minorities. In 2008, the last year the Bureau of Justice Statistics compiled a report on parents in prison and their minor children, 1.7 million children under age 18 were estimated to have a parent currently in prison (Glaze \& Maruschak, 2008). This number excludes children whose parents are incarcerated in jail and all children with previously incarcerated parents; including them would greatly expand the number of children impacted by parental incarceration. Black children and Hispanic children are much more likely than white children to have a parent in prison, 7.5 times and 2.5 times more likely, respectively (Glaze \& Maruschak, 2008). Wildeman (2009) calculated cumulative probabilities of risk and found that by age 14, the risk of parental imprisonment for black children was $25 \%$ compared to $4 \%$ for white children. Within each race, this risk was highest for children whose parents had dropped out of high school, reaching $55 \%$ likelihood of parental imprisonment for black children (Wildeman, 2009). These statistics indicate that the effects of parental incarceration are born disproportionately by black and low income families and communities. In addition, recidivism rates for former prisoners are high with $68 \%$ of state prisoners re-arrested for a new crime and $50 \%$ of state prisoners re-imprisoned within 3 years of release (Durose, Cooper, \& Snyder, 2014). Although it is not known what proportion of parents recidivate, it is reasonable to conclude that many families must deal with multiple incarcerations and disruptions to family life.

Given the U.S. reliance on incarceration as a drug and crime control measure over recent decades (Allard \& Greene, 2011), there is a growing number of young adults who experienced parental incarceration as children. Very little is known about the continuing effects of parental incarceration that linger into young adulthood. Developmental theory suggests that significant 
tasks are often fulfilled for young people from about ages 18 through the 20's. These include identity formation, establishing autonomy from parents, internalizing morality, formulating one's world view, career development, fostering effective relationships with an intimate partner, and raising children (Newman \& Newman, 2015). Given the importance of the young adult years in contributing to the social fabric through employment, forming one's own family, and public citizenship, it is important to understand whether and how parental incarceration shapes the lives and decision making of young adults. Young adults who experienced childhood parental incarceration are well positioned to reflect on and share their own experiences, including ongoing influences in their young adult lives. The purpose of this manuscript is to represent the subjective viewpoint of young adults who shared their experiences and perceptions about the ways that parental incarceration and family reentry during childhood continue to influence their young adult lives.

\section{Effects of Parental Incarceration in Young Adulthood}

Until recently, the effects of childhood parental incarceration on young adults were not a focus of empirical investigation. One of the earliest examinations is from a longitudinal study of 411 London boys, ages 8 and 9, first contacted in 1961 (Murray \& Farrington, 2005, 2008). Controlling for several individual and family risk factors, researchers found greater levels of antisocial behavior at age 18 (Murray \& Farrington, 2005). Murray and Farrington also found that even at age 32, well into adulthood, men who had experienced parental incarceration during childhood had heightened depression and anxiety (2008), and antisocial behavior (2005).

Scholars have begun to examine a broader range of economic, educational, and healthrelated effects of childhood parental incarceration on young adults and are finding that negative effects persist into adulthood. Several of these studies use data from the National Longitudinal 
Study of Adolescent Health (Add Health) (Foster \& Hagan, 2013, 2016; Lee, Fang, \& Luo, 2013; Miller \& Barnes, 2015). Miller and Barnes (2015), looking only at paternal incarceration and controlling for several potential confounders, found that two health-related variables (depression and serious injury in the past year), one economic variable (receipt of public assistance), and two education-related outcomes (whether or not a college graduate and satisfaction with educational attainment) remained statistically significant negative outcomes in young adulthood. Other studies examined the effects of both maternal and paternal incarceration, finding negative and differing effects depending on which parent was incarcerated. Childhood maternal incarceration has been significantly associated with depression in young adults and paternal incarceration with substance use problems, but not the converse (Foster \& Hagan, 2013). Lee et al. (2013) found that paternal incarceration was associated with a host of health-related problems including depression, PTSD, anxiety, high cholesterol, asthma, migraines, HIV/AIDS, and a general sense of poorer health. However, maternal incarceration was only significantly associated with depression. Examining social exclusion in young adults, comprised of personal and household income, perceived socioeconomic status (SES) and perceived powerlessness, Foster and Hagan (2016) found that childhood maternal incarceration significantly reduced perceived SES and increased perceived powerlessness. Paternal incarceration significantly reduced personal and household income and perceived SES. In addition, both paternal and maternal incarceration significantly negatively affected child prospects for completing college. Completing college did have a mediating effect on social exclusion for the young adult, reducing the impact of parental incarceration, suggesting the importance of educational interventions for children of incarcerated parents (Foster \& Hagan, 2016). 
One of the challenges with much of the empirical work related to the effects of parental incarceration during childhood has been the difficulty of isolating the effects of parental incarceration from other negative childhood contexts, such as poverty, child neglect or maltreatment, parental drug abuse, or living in disadvantaged communities (Hairston, 2007). Families at greatest risk of parental incarceration also experience many of these living conditions. In some cases scholars have used rigorous methodologies that allow the causal effects of parental incarceration, above and beyond other factors, to be examined. Mears and Siennick (2016), also using data from Add Health, examined 8 outcomes in early young (roughly the early 20s) and later young adulthood (roughly the late 20s). Using propensity score matching to come close to the rigor of experimental designs, individuals who reported that a parent had been incarcerated prior to age 18 were matched to individuals who reported no parental incarceration. Mears and Siennick (2016) found that adverse effects of parental incarceration increased over time. For the early young adults, it was associated with increased criminal offending, depression, marijuana use, lower educational attainment, and greater likelihood of living with a non-romantic partner. At the time of later young adulthood, criminal offending, depression, and marijuana use were even greater and in addition, heavy alcohol use and reduced earnings were now statistically significant outcomes. Taken together, the above studies provide strong evidence for the independent negative ramifications of childhood parental incarceration into young adulthood.

\section{Including Young Adults' Voices}

Although the literature related to the effects of childhood parental incarceration and reentry are expanding, few of the studies incorporate participants' own voices. (See Allard \& Greene, 2011; Cunningham \& Baker, 2003; Johnson \& Easterling, 2015; Luther, 2016; Nesmith 
\& Ruhland, 2008; and Yocum \& Nath, 2011 for exceptions.) As one participant told us during his interview, "the whole purpose I wanted to do this [interview] is I feel that no one tells your stories." Incorporating the perspectives of those who have experienced the phenomenon under study will enrich the findings gained through other methodological approaches and is vital to a full understanding and effective intervention.

\section{Methods}

\section{Sampling Procedure}

Fourteen young adults, ages 18 through 28 , consented to share their experiences related to parental incarceration and reentry during the time of adolescence and young adulthood. This manuscript reports findings related to participants' experiences as young adults. For findings related to participants' experiences during adolescence, see Authors (xxxx). The sample and methodology are the same as previously reported (Authors, $\mathrm{xxxx}$ ). Participants responded to one of several requests that went out with information about the study via emails, listservs, social media and posted fliers. Notices were sent via social work and criminal justice student listservs at two universities and were posted on departmental social media sites (i.e., Facebook, Twitter). The authors also contacted community agencies and asked them to post the flier or share information about the study with appropriate clients. Through these local contacts and additional agency-to-agency sharing of the flier, two community agencies that work with persons involved in criminal justice systems, one in the Northeast and one in the Midwest regions of the United States, offered to help with participant recruitment and did so through word of mouth and posting a flier. This broad recruitment strategy resulted in participants from four different states: Pennsylvania, New York, Missouri, and Washington. Five participants learned of the study via community agencies, five via student listservs, and four via word of mouth from others who 
knew about the study but were not participants themselves. Although the intent was not to seek out participants from such varied geographic regions or who had experienced parental incarceration across periods of childhood other than adolescence, recruitment proved to be a considerable challenge with a smaller-than-expected number of participants coming forward. To increase sample size, we included all prospective participants who met three predetermined study criteria regardless of geographic location or parental incarceration that extended beyond the participant's adolescent years.

The predetermined eligibility criteria prospective participants were screened for include: 1) be age 18 through 29 years old, 2) have a parent incarcerated for at least 3 months when the participant was 12 through 17 years old, and 3) the incarcerated parent was significantly involved in the adolescent's life prior to parental incarceration. Participants self-disclosed their age, estimated the length of parental incarceration during their adolescence based on memory, and decided for themselves whether their parent had been "significantly involved." A \$25 gift card was provided to participants as compensation for their time and any transportation-related expenses associated with participation. The study was approved by the Institutional Review Boards of the authors' universities.

\section{Study Design}

After giving informed consent, participants first completed a survey with primarily closed-ended questions related to demographic characteristics about themselves and their incarcerated parent. Face-to-face or telephone interviews were then conducted with each participant by the primary author or one of two graduate social work students. Interviews utilized an interview guide and were semi-structured, consisting of pre-developed, open-ended questions that helped move the participant's narrative through stages of parental incarceration 
and family reentry. Examples of prompts and questions from the interview guide relevant to the young adults' current experiences include the following: "Please tell me a little about your life now (employment, school, living situation, relationships, well-being)," "What is your relationship with your incarcerated parent like now?," "In what ways do you think your parent's incarceration still affects you?," Who helps you now?," and What would you like others to know about becoming an adult after having had these experiences growing up?" Participants were encouraged to share their experiences and perceptions and were given latitude to answer questions briefly or in detail. Gentle probing was used for clarification (e.g., "could you describe that?") or to ensure the participant was ready to move on to the next question (e.g., "is there anything more you want to say about that?"). Interviews ranged from 50-154 minutes, with a mean of 75 minutes. Interviews varied in length in part because some participants were more comfortable with the topic, more generally talkative, or had more stages of parental incarceration and family reentry to move through. The two graduate student interviewers were trained to conduct the interviews via orientation to the interview guide, role play in advance or joint conduct of the first interview with one author, and feedback and debriefing after the initial interviews.

\section{Data Analysis}

Qualitative analysis is especially helpful when the perspectives of participants as insiders are sought on a topic and it is important to understand the contexts that shape those perspectives (Padgett, 2017). The goal of understanding the experiences of parental incarceration and reentry from the perspectives of the children who had these experiences fits well with a qualitative approach. Using an approach informed by phenomenological analysis, our analysis goal is to describe the perceived impact of parental incarceration and family reentry on the current lives of 
a sample of young adults. Although disparate in many ways (e.g., geographic location, duration of parental incarceration, age at time of initial parental incarceration), all participants share the common phenomenon of being young adults who experienced parental incarceration prior to achieving adulthood. We considered their lived experiences, looking for salient themes across participants' accounts (Padgett, 2017).

All interviews were conducted, taped and transcribed using the same online transcription service prior to analysis. Once a transcript was received from the transcription service, one of the authors or graduate students listened to the interview audiotape while reading along with the transcript as a way of double checking the accuracy of the transcription, noting and correcting any detected errors. Analysis was then conducted on the proofread transcripts. First using an open coding process, all relevant participant comments, whether a phrase or whole story, to each question in the interview guide were placed in Word documents. This resulted in a Word file for each interview guide question and its corresponding participant responses. Throughout this process, the authors consulted with each other if there was uncertainty about where to place a comment. Because the transcripts in their entirety were reviewed, not just the section of the interview that directly asked each question, the result was a more complete array of responses for the next level of analysis. For example, it was not unusual for participants to discuss how an experience during adolescence continues to affect them now, even when the focus of the question was elsewhere.

During the next stage of analysis, both authors read through the created Word files in order to identify broad salient themes emerging from participants' experiences. Then, the first author conducted a more detailed, nuanced analysis of the salient themes relevant to the overarching research question addressed in this manuscript. Attention was paid to similarities 
and differences across participants' experiences and to the expressed dimensions of the broader themes. Written summaries were prepared that included the identified themes and their dimensions. These were reviewed by the second author, along with another review of each relevant Word file, to determine whether the conclusions drawn "rang true" to the narratives. Any areas of disagreement were discussed and reconciled by re-reviewing the original transcripts. To strengthen the trustworthiness of the study, strategies to enhance the credibility and confirmability of the data analysis were employed. These included engaging in a systematic and planned analysis process, the concerted effort to pay attention to the wide variation of participants' experiences expressed in the narratives, a careful recording of process decisions throughout, and continuous checking in and double-checking of each other's analysis process and conclusions.

\section{Sample Description}

Table 1 provides basic information about the sample. Participants were asked to describe in greatest detail the parental incarceration that was most significant to them. This was considered the primary incarceration, although it was not necessarily the parent's first incarceration. For seven participants, the primary parental incarceration began prior to adolescence, defined as 12-17 years of age, and either extended through adolescence or was followed by a subsequent incarceration that overlapped the adolescent years. Only two of the incarcerated parents did not live with their children prior to their incarceration. Participants reported that their parents were incarcerated for crimes involving drugs, fraud, arson, child molestation, and murder. They were incarcerated from six months to life, with 10 of the parents serving more than two years in prison. Six of the parents were incarcerated once; three were incarcerated twice; five were incarcerated three or more times. 
The current living situations of participants are varied, ranging from homelessness and precarious financial circumstances to stable housing, with the majority experiencing stability. Two participants recently released from prison or jail are working while staying at a mission for homeless individuals, hoping to get an apartment in the near future. One participant with her own home is not able to pay the utility bill and thus has not lived there for a couple months, choosing instead to relocate herself and her 3 children to her mother's. One 22-year-old college student is having difficulty making ends meet, particularly now after her father's third incarceration and the loss of his financial assistance. She has been close to eviction more than once for failure to pay rent at her off-campus house. Those with more stable housing live on campus (2 participants), live with parents and step-parents (3), have a paid live-in position (1), or are independent, living on their own or with their own families (4). All 14 participants are in college (8) and/or are employed at least part-time (10). Four participants are in committed, intimate partner relationships. Six of the participants have children, and another is pregnant with her first child.

\section{Findings}

This manuscript focuses on the perspectives of the participants related to their adult lives. We address the following general research question: In what ways do young adults believe they have been impacted in young adulthood by the earlier experiences of parental incarceration and reentry? Participants' current relationships with their parents demonstrate important impacts of parental incarceration on this primary parent-child relationship in young adulthood. In addition to profoundly affecting this specific relationship, participants also describe other ways they perceive their lives remain influenced by parental incarceration. Salient themes that emerged have to do with the challenges of forging relationships with other people and the need to 
continue to deal with strong emotions that resurface. For a small minority of participants, the ongoing struggle is about keeping themselves on track and out of jail. Finally, participants identified some positive aspects to their experience of parental incarceration.

\section{Relationships with Incarcerated Parent}

Participants were asked about the nature of their current relationship with the parent who was incarcerated during the participant's childhood. We wanted to understand, from the participants' perspectives, whether and how this primary child-parent relationship had been impacted by the incarceration. Of these parents, two have sentences that will keep them incarcerated for the duration of their lives and one recently began his third incarceration.

Five types of relationships between these young adults and their previously or currently incarcerated parents emerged from the thematic analysis. The types can be characterized as five dimensions along a continuum from "permanently nonexistent" on one end to "positive" on the other. Most participants are somewhere in the middle. In Figure A, the number within each parenthesis indicates the number of participants whose parental relationship is best characterized by each dimension. The 24-year-old participant in the "permanently nonexistent" category does not want to have contact ever again with her previously incarcerated father. She has not seen him since age 12 , has not been in touch with him, and has no intentions of doing so. Her father was incarcerated for child molestation within the family when she was in the second grade and was released within the last few years.

For three participants, the relationship with their parent is currently nonexistent, but they anticipate this will change or are open to that possibility. One of these three participants stopped contact four years ago when her imprisoned father did not answer the heartfelt letter with 
detailed questions that she wrote him when she was in high school. She was deeply hurt by his lack of response and has not forgiven him. She stated,

I sent a letter - very detailed, very long - that took a lot out of me because I didn't talk about it for a long time. So, writing that and expressing my feelings to him about how I felt... and then, getting a letter from him that didn't address any of the things that I put in my letter, basically, I would say that was the time that my heart was broken.

Although she does not plan to seek him out, she will talk to him if he initiates contact, and thus this relationship is characterized as "temporarily nonexistent," although over time it could conceivably become "permanently nonexistent" if nothing changes. Another participant in this category stated that she is upset with her father and plans to receive counseling to work through her own feelings before revisiting a relationship with him. She explained,

I'm going to go start counseling to try to be able to move my hurt and my anger and frustration, before I can really talk to him and have a sit-down talk....I think he's very disappointed with me, but I think I'm just trying to process myself before I go home and try to have a family meeting with him and really talk about where I'm hurt, why I'm hurt without getting angry at him, so I've become a little bit disconnected for the sake of our relationship.

The last participant in the "temporarily nonexistent" relationship category stated that he has not talked to his father for a month but stills feel connected to him. He explained, I just came home from jail. I did three years. And my father was there for me. He was the first person that wrote me, sending me money....It was just like, you've got nobody, and then he was there for me. We're on bad terms right now for some stupid stuff....In general, we're good....It was just a money situation that we just fell off a little bit. But 
I'm probably going to call him today. We stopped talking for like a month. But he'll be asking about me. I'll still be asking about him. So I know it isn't really a beef, but we just stopped talking.

It is clear the participant sees this current estrangement as temporary.

The majority of participants' relationships with previously and currently incarcerated parents fall within the "precarious" or "restricted and active" dimensions (see Figure A). "Precarious" relationships are currently ongoing but are unstable or not mutually supportive. In two cases the participants see their parent regularly or talk frequently, but the young adult sees the parent as one who is "just a friend" and not as someone they can depend on. One male participant explained,

We see each other regularly all the time. We have a good relationship. We call on each other and stuff like that. He calls me all the time, he comes over all the time. Like I said, I'm better off than he [father] is. So I'm not bragging or nothing like that, I'm just saying that because of the mistakes he made in his life...I still can't call upon him when I get in a jam. He can't help me. But, I mean, I'm at a point where I don't hold that against him. Another participant has seen his mother a few times since his own release from jail and was shocked when his mother bought him clothes when he got home. He described this kindness as being totally out of character. He stated,

She's [participant's mother] been clean now for probably, like, 97 days.... When I came home my clothes was stolen. My clothes got stolen during my incarceration so she bought me a pair of sweatpants, some sneakers, and stuff like that and that was shocking....We're doing better. We're actually communicating instead of just arguing. 
The last participant in the "precarious" relationship category is deeply involved with and is caretaker for her previously incarcerated mother who is very sick with diabetes and chronic obstructive pulmonary disease. The participant describes her mother as mean and unmotivated to improve her health. Her mother repeatedly tells her that "you all [participant and siblings] don't care and you all don't help me." She was "running the streets and doing drugs" for much of the participant's childhood and was incarcerated for drug possession. Although the participant states she has forgiven her mother and tries to enjoy the remaining time with her mom, she is overwhelmed by the caretaking responsibilities and describes a relationship that takes an incredible toll on this young adult.

Participants whose relationships with their previously or currently incarcerated parent are categorized as "restricted and active" have ongoing relationships with their parent but the type or frequency of contact is limited by the young adult. One of these participants limits contact to telephone conversations, texting, and social media, communicating via these routes four to six times a week, but not visiting in person. Even while limiting contact with her father, what she admitted that she wants might be out of reach - for her relationship with her father to return to the fun and comfortable one they shared when she was age 11. She is now 18-years-old. Another participant, after sorting out for herself what she wanted, explained to her father that she did not want him to call her every day.

The next fall, I went to college, and we were in an okay spot. He would call me every day just to say 'hi' and 'I love you.' I didn't like it, but I also didn't know how to not have that happen anymore. My sophomore year, I studied abroad, so he couldn't afford to call me because I was living in Europe. That year, I had a lot of opportunity for some growth, and discovery, and figuring out how to assert myself and what I wanted, and that 
that was okay. When I came home, I was able to say, 'Dad, I don't want you to call me every day. I want to talk to you, but not every day. Let me call you sometimes.' Since then, we've had a really good balance. We talk probably every three days, sometimes really briefly, and sometimes we talk for a while longer.

This relationship may change with her father's recent relapse into drug use, a change she is not sure how to handle. She feels like she has to take care of her father and yet she does not want to do so. It is possible that this relationship may shift on the continuum to the "precarious" dimension.

Concerns about role reversal are also evident for the 27-year-old participant who described strained weekly conversations with her previously incarcerated mother.

When I first moved here three years ago, I talked to her every day, talked to her and my dad every day. Now, I talk to her every now and then. Not every now and then, I talk to her maybe once a week. I try to. I kinda made it clear to her this year in particular that this is my last year of grad school so I probably won't have enough time to really call you every day....The conversations are usually pretty strained. She usually talks about the same thing over and over again and I'm like but the roles have changed. It's sort of like I'm the mother and she's the daughter now.

The last participant fitting the "restricted and active" dimension talks regularly to her father and gives money to him at times. In turn, she receives some help with home maintenance and childcare. Even with this mutually beneficial relationship, she will soon be moving out-ofstate to attend graduate school and live near her fiancé. She is glad to be moving away, including from her father's needs. She stated, 'I'm going to be quite a ways from everybody and I'm happy about that. I don't want to deal with anybody else's problems but my own." 
Two participants described relationships that have steadily improved over time and are now quite positive. Both of these participants' parents are currently incarcerated. One participant's father is on his third incarceration, even so this young adult describes a relationship that is stronger now than during previous incarcerations. They speak regularly on the phone and sometimes communicate via email. She states that it has helped to no longer judge their relationship based on her perceptions of other people's family lives and what parent-child relationships should be. The other participant's father remains in prison for life for murder, having gone in when she was only six-years-old. At the age of 20 she took the initiative to go out-of-state to visit her father. She explained a bit more:

After meeting him when I was 20, I was really curious and at that time I was also getting strong into my church and learning what it meant to forgive and move forward. So it was just something that was on my heart for a really long time, so I went against the...advice of others [and]went to go meet him for the first time. After that, two years later, so when I was 22, I went back for Christmas break and I saw him every day for a week because I was just curious. What was he like before? Who was he? ...nobody would really tell me those things. So finally I was like okay I am going to have whatever kind of relationship I can with him. I need to do this for me because it's not healthy for me to have such bad feelings towards my dad.

Her father had written her regularly throughout her childhood even though she did not respond to his letters and was extremely angry with him during most of her adolescence. They currently communicate through frequent and regular letters and infrequent phone calls from prison.

In almost all cases, parent-child relationships continue into young adulthood for these participants. Many are tenuous and many others are restricted by choice or by legal 
circumstances. These parents are not able to assist their young adult children in ways that are typical of many families. For example, they are not in a position to financially provide a safety net. In addition, with the rare exception, their own lives are troubled enough or the parent-child relationships have been damaged to such an extent that their adult children do not experience consistent emotional support from them.

\section{Challenges with Other Relationships}

Damaged trust and the belief that others cannot be counted upon are described by five of the 14 young adults as expressly hindering their ability to form and maintain strong mutual relationships with partners or close friends. One 27-year-old female expressed this belief in this way, “I don't trust people very much....So as far as building lasting relationships, I'm not very good at that." Another 22-year-old male simply said, "I don't really trust anybody." Perhaps the saddest and most extreme expression of damaged trust and its relational effects was expressed by a 25-year-old male whose father was incarcerated when the participant was age 12 and then again very soon after his father had been released when the participant was age 16. "I have a lot of trust issues. I have a big wall put up until this day. I walk around and I don't let nobody [sic] in." A sixth participant reflected on the progress she has made in her ability to seek out a mutually beneficial romantic relationship. She described how she sought out male partners as an adolescent and young adult who had similar lifestyles to her drug-addicted and frequently incarcerated father. Now 28-years-old, she has been married and divorced twice. Her first marriage at the age of 22 ended when her husband went to prison for five years. Her second husband was abusive; after a time she mustered the strength to leave him. All four fathers of her four children were imprisoned at some point. She explained, 
I think my father's incarceration put into my head that going to prison was okay or it was regular or normal. So I think I sought out men I shouldn't have, that had the same or similar lifestyles and that became okay to me. Now I can look back and be like, 'I shouldn't have been messing with that person in the first place.' But some of the behaviors and mannerisms my dad had, I tolerated in other people and I wish that I didn't. In speaking about her current ability to build positive relationships, she reflected, "I think that I'm mentally able to handle situations and men a little bit differently now....my fiancé now is in the military and is relatively well off. So it's a different kind of relationship."

\section{Negative Emotions}

Although the specific emotions varied across participants, nine young adults discussed the need to continue to manage intense and troublesome emotions as a lingering challenge associated with having had an incarcerated parent. Most commonly expressed were self-doubt (3 participants), anger (4), and regret or sadness (5). Self-doubt was expressed as the feeling that one is never doing enough. Two expressing self-doubt linked this concern to the stigma of having an incarcerated parent. For example, one 27-year-old participant stated,

I'm running from having a stigma placed on me because of who I am and the things that I've been through....I'm doing so many wonderful things...I just don't feel like it's enough. Like I'm not doing enough to not be...judged [emphasis added]. A 22-year-old expressed the worry that "if I made a mistake, I feel like people would say, 'well, look who her father is."”

Two of the four male participants described their struggles to manage their anger. One steers away from certain kinds of relationships because of what he might do. He explained: 
The anger is still there, so it makes me, I can't be around certain people. Like now, I'm scared to have kids. I don't have no [sic] kids. I'm scared to have kids because I might not have no $[$ sic $]$ compassion....I can't have no compassion for my child, because I never dealt with it. Her problems or his problems, I might think like, 'that ain't no damned problem.' I come from a real life problem. So I don't really have no compassion, and then I don't trust. Everybody ever that I ever let in and try to love, they either broke that trust or they broke that bond somehow, so it's hard to find a relationship. I'm more alone...I'm more aggressive than others.

For this 25-year-old, the anger and trust issues are tied together. One female participant who talked about anger as a lasting effect is angry "especially with the justice system." This 22-yearold also described an ongoing fear of instability and the feeling that she was somehow responsible for her father's incarceration. She was 17 -years-old when her father went to prison for three years for a drug-related charge. Another female participant stated, "I have a lot of anger for my dad for the way we lived. It was hard for me to empathize with anything." Although the anger is still present, it has eased over time as she has gained independence from her father.

As participants reflected on the ways parental incarceration continues to influence them, they expressed regret or sadness for lost past or future opportunities to spend quality time with a parent and share meaningful life moments. For example, the 28-year-old who is caring for her sick mother still keenly feels the loss of quality family time during adolescence when her mother was doing drugs and not present. She reflected, "We [participant and her siblings] wanted to spend that quality time with her. We wanted to take her places. We feel like we still missed out on all that." The 24-year-old female whose father is in prison for life regrets that he cannot walk 
her down the aisle at her wedding. In one case, this regret extends to sibling relationships. One participant described how all the "crap" from the past weighs down the relationships she and her sisters try to maintain. The parents, who should be the glue, do not hold them together and "everybody gets sick of being the parents or trying to hold us together."

For the majority of participants, living with the painful emotions associated with their parent's behavior and incarceration is an ongoing burden. Repression has been one strategy used to handle these emotions including choosing not to talk about the family's history. One 22-yearold female whose father was incarcerated for three years when she was 17 -years-old succinctly illustrates what others also mentioned, "I think this was the first time I've been able to talk about it from day one to now...I didn't know it was going to be so hard....Now that I went into detail, it's actually very emotional." Another 24-year-old graduate student sums up the emotional work this way:

A common question in social work [field of study] is when does that work ever end? Are we ever going to be okay? I think the answer is probably no. We're always going to have work to do. It's just a matter of acknowledging the work and pain that's still there, and doing my best to move forward with it. I try not to go backward.

\section{Keeping on Track}

Although only relevant to a small number of participants, some continue to struggle with staying out of trouble. One 22-year-old male, released six months ago after serving 30 months in prison for a gun charge, admitted he still gets into fights and is tempted to run the streets. This young man has been fighting others for some time. For example, at the age of 12, he described his reaction to witnessing his father's re-arrest. He stated: 
Then all of a sudden, he just went back to jail. It didn't make any sense to me. It still doesn't make sense to me, now. He just went back. Out of the blue....They [police] raided the house....Police were kind of rough. Put their hands and feet on him [father]. My mom almost went to jail that day because she was trying to fight them. We [participant and his brothers] were trying to fight them.

Another 22-year-old male, whose mother was incarcerated when he was 17, finds staying on track to be a daily and fierce challenge. He described his lifestyle just prior to going to jail for eight months for violating a protection order and possession of stolen property the following way:

I ain't [sic] really had nowhere to go - sort of, homeless I want to say - just jumping around from place to place. Just going to the bars all the time...following the path that my mother was on, basically, and it was just real bad....Waking up and not even knowing how I got there or where I'm at, at that point in time. That's how it was. Staying up days not going to sleep.

This young man had only been out of jail five weeks at the time of his interview. He explained his biggest difficulty is staying sober. "I'm trying to stick with it and that's hard." He admitted he does not know how to cope. This young man's mother was so abusive throughout his life that he was relieved when she was incarcerated. In his case, it is reasonable to assume that his total childhood family experiences, and not solely his mother's criminal behavior and incarceration, created lasting and negative impacts.

Finally, one 22-year-old female took her father's recent and third incarceration really hard. She explained that she had been ultra-responsible up until this point, but when she learned her father was going back to prison she decided to let go and have fun. With a friend's 
encouragement, she attempted to carry drugs into a concert, was caught and arrested, and ended up having to face criminal charges and her university's judicial affairs office. It was at this point that she started seeing a psychologist and was diagnosed with "manic depression" and a generalized anxiety disorder. Slowly she has been working to understand the impacts of her father's behavior on her own. Unlike the two males who struggle with staying out of trouble, her engagement in illegal behavior was described as a one-time lapse in judgment.

\section{Positive Aspects}

Despite the difficult challenges these young adults seek to overcome, not all expressed outcomes of parental incarceration are negative. Six participants talked specifically about their educational goals and career choices, in criminal justice, social work, and law, which stem directly from a motivation to help others. For example, one participant stated,

I know my dad going to prison is what encouraged me to pursue a career in law, because it just seemed really unfair. I used to believe that I had to help my dad get out of prison, that I had to do something. So that's what inspired me toward criminal justice.

Similarly, another participant explained,

I became very passionate about helping other people because I felt like what happened to my dad, there were a lot of other societal issues that went into it. I felt like there was a lot of outside, societal things that contributed to it and that, if I could be of any kinda help to other people - I really became very, very, very, very passionate about it, which has led me to be a social work major, to wanna be a future lawyer....I see it, like I've said, as a positive thing that's helping me, basically, decide what I wanna do with my life. It's been that guiding sense. So I explained to people when they were like, 'Why do you wanna be a lawyer? Why do you wanna be a social worker?' 'My dad was incarcerated 
and I feel like there's things I can do to help people.' That explains... why I'm in the programs that I am.

A 24-year-old participant currently working in public child welfare and whose father was incarcerated for 15 years for child molestation when she was age eight, stated she wanted to help other people "because I know it's possible to be successful when you come from a really rough, crappy situation." Part of this desire to help is an effort to prevent others from going through what they experienced or to assist those who are dealing with parental incarceration. One participant whose father remains incarcerated, expressed this desire this way. "I would love a doctorate degree and I really want to open my own nonprofit for at risk youth and kids of incarcerated parents." Two participants also talked about their greater awareness, based on past experiences, of the societal factors that are linked to incarceration. They use this knowledge to inform discussions with others and in one case to work with teenagers involved with the criminal justice system. Although participants still clearly struggle with relationships, intense emotions, and in some cases staying on track, there are indicators of resilience across this group of young adults, evidenced in part by their employment and educational goals and accomplishments.

\section{Discussion}

This study provides a rare opportunity to hear firsthand from individuals who experienced parental incarceration during their childhood. They reflect on the ways parental incarceration and family reentry continue to impact their lives as young adults. Their experiences are varied, with a few landing firmly on their feet and others constantly struggling to overcome their life circumstances. Most participants experience something in-between these outcomes. Mears and Siennick (2016), in describing the life course perspective, posit that parental incarceration creates a significant turning point for children, altering their trajectories in 
ways that produce long-term adverse effects long after childhood. Parental incarceration was indeed described as an important turning point in our participants' lives. For a couple participants, parental incarceration in itself was not a negative event given the sexual abuse or violence the offending parent imposed on the family. However, even for these children, parental imprisonment did not necessarily improve their overall life circumstances because other challenges increased, such as poverty and neglect. It is hard to tease out the negative effects of parental imprisonment from those of other childhood contexts, such as poverty, parental drug abuse, and child neglect or maltreatment, and this study does not do so. At the same time it is also clear that this group of young adults, with only a few exceptions, perceive parental incarceration as unhelpful to them, their parents and families. The majority continues to struggle with powerful and negative emotions that influence mental health and self-efficacy. Most experience long-term diminished relationships with the (previously) incarcerated parent. In addition, as they are in young adulthood, they cannot count on their incarcerated parents for financial assistance or even consistent emotional support, eroding the physical and emotional safety nets that young people so often rely upon as they become established as adults. Parental incarceration during childhood is not something one recovers from simply because adult status is achieved.

\section{Limitations}

Methodological challenges in completing the study included difficulty obtaining participants. Although we recruited widely using various techniques over a two-year time period, only 14 participants came forward. In addition, because we had difficulty gaining participants we cast a wide net, resulting in more diversity in the sample (e.g., geographic location) than originally intended. Nonetheless, all participants provided firsthand descriptions 
of a shared phenomenon, parental incarceration of a parent who had been significantly involved in their lives during adolescence. Salient and common themes emerged across their narratives. To date, this description is largely lacking in the empirical literature. Those who did consent to be interviewed provide one possible explanation for the difficulty with participant recruitment. Five young adults explained that they seldom talk with anyone about their experiences; they prefer to try to forget them and move on. One, expressing a common sentiment, stated that "when [thoughts of her parent's incarceration] come up, the emotions are intense" so she continues to repress her thoughts and keep them to herself. A few of the participants had siblings that had also experienced parental incarceration while adolescents, but when the interviewer asked whether these siblings might also like to be interviewed, the answer was negative. The participants conveyed that their siblings were not willing to discuss their experiences with others and were really struggling to cope with their pasts.

Despite the small number of participants, there is growing evidence that sample sizes as small as six individuals in qualitative studies are sufficient for adequately surfacing the majority of themes found in larger samples (Francis et al., 2010; Guest, Bunce, \& Johnson, 2006; Hennink, Kaiser, \& Marconi, 2016), providing confidence that a robust array of relevant themes for this descriptive study are present among our sample. University-based recruitment strategies yielded the majority of our participants and many of them are current college students. It is likely that our sample is comprised more heavily of young adults who are successfully weathering the difficulties of childhood parental incarceration. Future research might address these limitations by finding additional access points to young adults who have experienced parental incarceration, including sibling groups. In addition, our participants were not available for multiple or follow-up interviews, typical of a phenomenological approach (Padgett, 2017). 
Qualitative research studies that are able to employ strategies such as conducting multiple interviews with participants or member checking would increase depth and confidence in the findings' dependability.

\section{Practice and Policy Implications}

From a policy perspective, to reduce the number of families and communities that parental incarceration touches, when possible and much more frequently, alternatives to incarceration such as drug or alcohol treatment and restorative justice community-based approaches should be employed with offending parents. At least half of our participants grew up under the weight of parental substance abuse. Restorative justice's emphasis on repairing harm rather than on punishment and seeking to address the concerns of both offender and community, would provide options that are responsive to the well-founded critique that incarceration in and of itself does not help most offenders and families in the long-run. (See Umbreit \& Armour, 2011, for extensive information on restorative justice.) Future research could compare the financial, emotional, health-related, and future criminal behavioral outcomes for offenders and families experiencing traditional criminal justice responses such as incarceration and alternatives to incarceration intended to treat and restore. If incarceration of the offending parent is necessary for the protection of children or others, family members without strong support networks will need assistance and support as they adjust to this significant transition.

Young people experiencing and overcoming the impacts of parental incarceration need support to assure their wellbeing. Incarceration of a household member is one of the adverse childhood experiences associated with long-term negative outcomes for children (Felitti et al., 1998; Gjelsvik, Dumont, Nunn, \& Rosen, 2014). There is increasing evidence that trauma profoundly affects child development and one's future health (Hodas, 2006), and that childhood 
parental incarceration can produce emotional effects into young adulthood such as those exhibited by our sample (Morgan-Mullane, 2017). Manning (2011) eloquently describes the traumatic impact for children of observing a parent's arrest. Four of our participants told us they witnessed parental arrest as young children or in early adolescence. Although they did not explicitly connect this experience to ongoing difficulties managing intense negative emotions and forming mutually positive close relationships, these outcomes mirror those described in the literature as trauma-related stress symptoms (Morgan-Mullane, 2017). The few participants who could not think of anyone who helped them in childhood or helps them now expressed hopelessness about their lives and futures. They work to maintain control by disengaging, a maladaptive coping strategy. They struggle the most with anger, addiction, and distrust and need intervention if long-term positive trajectories are to develop for them in adulthood. These types of responses indicate the need and importance of trauma informed care for children experiencing the many associated traumas of parental incarceration (see Morgan-Mullane for several examples, 2017) and for young adults who continue to struggle with the aftermath.

Trauma informed care recognizes the connections between current symptoms and behaviors and the individual's past traumatic experiences (Hodas, 2006). The purpose of trauma informed care is to help the individual heal, and professional interventions are directed toward this end. Specific approaches, such as Trauma Focused Cognitive Behavioral Therapy, is a promising manualized approach with demonstrated effectiveness for treating trauma in children, although it works best with children with depressive symptoms and a willingness to engage in the process (Morgan-Mullane, 2017). Although a couple of participants reported being offered counseling at the time of parental incarceration, they told us they were reluctant to ask for help as children. Nevertheless in retrospect as young adults, they recognize the need for emotional and 
practical support from others, with some expressing surprise at the intensity of the lingering emotional impact of their parent's incarceration. More informally, teachers, extended family members, church and faith-based members, neighbors and community agency volunteers could all help by serving as mentors and positive role models, building affirming relationships with young people over time. Some of the participants themselves who have made important progress in their own healing would make good mentors to adolescents experiencing parental incarceration.

Higher education is credited by some of our participants with facilitating their ability to come to terms with parental incarceration. Concepts they learned in their courses, peers they met during college, and living on their own in the university's structured and supportive environment all played a part. Almost half of the participants indicated that they chose social work and criminal justice educational degrees because of their backgrounds. They viewed this choice as a way to turn a painful situation into something beneficial for others. This qualitative finding fits with Foster and Hagan's (2016) quantitative finding that successful completion of college by children of incarcerated parents reduced negative parental imprisonment effects by 14 to $50 \%$. Interventions that inspire and assist with college readiness, application to, and successful completion of college may be especially effective for young adults who have experienced parental incarceration.

Finally, participants expressed appreciation for the opportunity to "tell their story." This had value in and of itself in promoting healing. Talking or healing circles, traditional practice for many indigenous people, have been associated with improved quality of life (Mehl-Madrona \& Mainguy, 2014). This approach might be a means by which young people are offered a safe space to share their experiences of parental incarceration, reentry, and re-incarceration. Service 
practitioners and researchers should create opportunities to encourage adolescents and young adults, impacted by parental incarceration and its challenges, to be heard. 


\section{References}

Allard, P., \& Greene, J. (2011). Children on the outside: Voicing the pain and human costs of parental incarceration. Retrieved from Justice Strategies website:

\section{Www.justicestrategies.org}

Authors, $\mathrm{xxxx}$.

Cunningham, A., \& Baker, L. (2003). Waiting for Mommy (ISBN: 1-895953-24-3). London, Ontario: Centre for Children and Families in the Justice System.

Durose, M. R., Cooper, A. D., \& Snyder, H. N. (2014, April). Recidivism of prisoners released in 30 states in 2005: Patterns from 2005 to 2010 (NCJ 244205). Washington, D.C.: U.S. Department of Justice.

Felitti, V. J., Anda, R. F., Nordenberg, D., Williamson, D. F., Spitz, A. M., Edwards, V., ...Marks, J. S. (1998). Relationship of childhood abuse and household dysfunction to many of the leading causes of death in adults: The Adverse Childhood Experiences (ACE) Study. American Journal of Preventive Medicine, 14(4), 245-258.

Foster, H. \& Hagan, J. (2013). Maternal and paternal imprisonment in the stress process. Social Science Research, 42, 650-669.

Foster, H., \& Hagan, J. (2016). Maternal and paternal imprisonment and children's social exclusion in young adulthood. Criminology, 105(2), 387-429).

Francis, J. J., Johnston, M., Robertson, C., Glidewell, L., Entwistle, V., Eccles, M. P., \& Grimshaw, J. M. (2010). What is an adequate sample size? Operationalising data saturation for theory-based interview studies. Psychology and Health, 25(10), 12291245. 
Gjelsvik, A., Dumont, D. M., Nunn, A., \& Rosen, D. L. (2014). Adverse childhood events: Incarceration of household members and health-related quality of life in adulthood. Journal of Health Care for the Poor and Underserved, 25(3), 1169-1182.

Glaze, L. E., \& Maruschak, L. M. (2008, revised 2010, March). Parents in prison and their minor children (NCJ 222984). Washington, D.C.: U.S. Department of Justice.

Guest, G., Bunce, A., \& Johnson, L. (2006). How many interviews are enough?: An experiment with data saturation and variability. Field Methods, 18(1), 59-82.

Hairston, C. F. (2007, October). Focus on children with incarcerated parents: An overview of the research literature. Baltimore, MD: Annie E. Casey Foundation.

Hennink, M. M., Kaiser, B. N., \& Marconi, V. C. (2016). Code saturation versus meaning saturation: How many interviews are enough? Qualitative Health Research, 1-18.

Hodas, G.R. (2006, February). Responding to childhood trauma: The promise and practice of trauma informed care. Retrieved from Pennsylvania Office of Mental Health and Substance Abuse Services website: www.dhs.pa.gov/cs/groups/public/documents/manual/s_001585.pdf

Johnson, E. I., \& Easterling, B. A. (2015). Coping with confinement: Adolescents' experiences with parental incarceration. Journal of Adolescent Research, 30(2), 244-267.

Lee, R. D., Fang, X., \& Luo, F. (2013). The impact of parental incarceration on the physical and mental health of young adults. Pediatrics, 131(4), e1188-1195.

Luther, K. (2016). Stigma management among children of incarcerated parents. Deviant Behavior, 37(11), 1264-1275.

Manning, R. (2011). Punishing the innocent: Children of incarcerated and detained parents. Criminal Justice Ethics, 30(3), 267-287. 
Mears, D. P., \& Siennick, S. E. (2016). Young adult outcomes and the life-course penalties of parental incarceration. Journal of Research in Crime and Delinquency, 53(1), 3-35.

Mehl-Madrona, L., \& Mainguy, B. (2014). Introducing healing circles and talking circles in primary care. The Permanente Journal, 18(2), 4-9.

Miller, H. V., \& Barnes, J. C. (2015). The association between parental incarceration and health, education, and economic outcomes in young adulthood. American Journal of Criminal Justice, 40, 765-784.

Morgan-Mullane, A. (2017). Trauma Focused Cognitive Behavioral Therapy with children of incarcerated parents. Clinical Social Work Journal. Published online https://doi.10.1007/x10615-017-0642-5

Murray, J., \& Farrington, D. P. (2005). Parental imprisonment: Effects on boys' antisocial behavior and delinquency through the life-course. Journal of Child Psychology and Psychiatry, 46(12), 1269-1278.

Murray, J., \& Farrington, D. P. (2008). Parental imprisonment: Long-lasting effects on boys' internalizing problems through the life course. Development and Psychopathology, 20, 273-290.

Nesmith, A., \& Ruhland, E. (2008). Children of incarcerated parents: Challenges and resiliency, in their own words. Children and Youth Services Review, 30(10), 1119-1130.

Newman, B. M., \& Newman, P. R. (2015). Development through life: A psychosocial approach $12^{\text {th }}$ ed.). Stamford, CT: Cengage Learning.

Padgett, D. K. (2017). Qualitative methods in social work research (3 ${ }^{\text {rd }}$ Edition). Thousand Oaks, CA: Sage. 
Umbreit, M., \& Armour, M. P. (2011). Restorative justice dialogue: An essential guide for research and practice. New York: Springer.

Wildeman, C. (2009). Parental imprisonment, the prison boom, and the concentration of childhood disadvantage. Demography, 46(2), 265-280.

Yocum, A., \& Nath, S. (2011). Anticipating father reentry: A qualitative study of children's and mother's experiences. Journal of Offender Rehabilitation, 50(5), 286-304. 
Table 1. Sample Characteristics

\begin{tabular}{|c|c|}
\hline Characteristic & $\begin{array}{l}\text { Participants } \\
(\mathrm{N}=14)\end{array}$ \\
\hline \multicolumn{2}{|l|}{ Age at Interview } \\
\hline 18 & 1 \\
\hline 19 & 1 \\
\hline 22 & 5 \\
\hline 24 & 3 \\
\hline 25 & 1 \\
\hline 27 & 1 \\
\hline 28 & 2 \\
\hline \multicolumn{2}{|l|}{$\begin{array}{l}\text { Age at Primary Parental } \\
\text { Incarceration* }\end{array}$} \\
\hline 2 years & 1 \\
\hline $6-8$ years & 3 \\
\hline $9-10$ years & 2 \\
\hline 11-12 years & 4 \\
\hline 16-17 years & 4 \\
\hline \multicolumn{2}{|l|}{ Gender } \\
\hline Female & 10 \\
\hline Male & 4 \\
\hline \multicolumn{2}{|l|}{ Race/Ethnicity } \\
\hline African-American & 6 \\
\hline Caucasian & 6 \\
\hline Hispanic & 2 \\
\hline \multicolumn{2}{|l|}{ Incarcerated Parent } \\
\hline Biological Father & 9 \\
\hline Stepparent Father & 2 \\
\hline Biological Mother & 3 \\
\hline
\end{tabular}

*For this study, the primary incarceration was the parental incarceration that the participant identified as most significant to him/her. It was not necessarily the parent's first incarceration.

This table is derived from one previously published in Authors, xxxx. 
Figure A. Continuum Depicting Relationships Between Young Adults and Incarcerated Parents 